\title{
EXTENTIONAL FAULT PADA DAERAH COMPRESSIVE TECTONIC ZONE SEBAGAI BATAS CEKUNGAN DI JAWA TENGAH SELATAN
}

\author{
Asmoro Widagdo $^{\mathrm{a}}$, Aang Panji Permana ${ }^{\mathrm{b}}$ \\ ${ }^{a}$ Geology Department, Engineering faculty, Universitas Jenderal Soedirman, Purwokerto-Indonesia \\ b Geology Department, Faculty of Mathematics and Natural Science, Universitas Negeri Gorontalo, Gorontalo-Indonesia
}

\section{ARTICLE INFO}

\section{Article history:}

Received: 19 November 2020

Accepted: 19 January 2021

Published: 27 January 2021

\section{Keywords:}

Compressional Stress; Extensional; Mountain; Normal Fault

\section{Corresponding author:}

Asmoro Widagdo

Teknik Geologi, Universitas Jenderal

Soedirman, Purwokerto, Indonesia

Email: asmoro.widagdo@unsoed.ac.id

\begin{abstract}
The extensional structure as a normal fault could be found in many places at the southern part of Java compressive tectonic regime. The research area is in the eastern part of the South Serayu Mountains. This normal fault structure is the boundary of the South Serayu Mountains at the eastern part with Kulon Progo Tertiary volcanic Mountains. In the field, these normal fault lineament zones create the Bogowonto river as a boundary of two different geological styles. The influence of this structure on the geological dynamic of the South Serayu Mountains and the Kulon Progo Mountains is important to be explained. The study was conducted by measuring and analyzing fault data and lithology that developed in the area around the two basins boundary. The distribution of the Kulon Progo volcanic rocks indicates the presence of the extensional fault structure. The volcanic facies distribution of the volcano is cut and becomes narrow in the west, while the northward is very wide. Normal fault striations analysis on the fault plane along the fault line shows the least stress trending west-northwest that has worked to create North-South normal faults. The faultcontrolled by stress with the vertical main compression area. They have worked to create North Northeast-South Southwest (NNE-SSW) normal faults with westward dipping.
\end{abstract}

Copyright (C) 2021 The Authors This open access article is distributed under a Creative Commons Attribution (CC-BY) 4.0 International license

\section{Pendahuluan}

Tatanan tektonik baru terjadi di Samudera Hindia pada Oligosen Akhir hingga busur gunung api baru terbentuk di selatan Jawa (Bachri, 2014). Pada waktu konfigurasi tektonik baru terjadi, terbentuk empat sesar utama, yakni Sesar Citanduy, Sesar Kroya, Southern Hinge Line dan Sesar Purworejo di sisi timur pegunungan Serayu (Sujanto \& Sumantri, 1977). Sesar Purworejo ini kemudian disebut sebagai Sesar Normal Bogowonto, merujuk pada jalur kelurusan sesar yang kemudian membentuk Sungai Bogowonto. Sesar yang menjadi batas sisi timur Pegunungan Serayu selatan yang bersifat kompresif ini belum dikaji lebih lanjut hingga kini. Lokasi daerah penelitian di dalam konstelasi Pulau Jawa ditunjukkan pada Gambar 1.

Sesar Normal Bogowonto terletak diantara Pegunungan Serayu bagian selatan di wilayah Purworejo dan Pegunungan Kulon Progo. Kabupaten Purworejo dan Pegunungan Kulon Progo merupakan bagian dari wilayah Provinsi Jawa Tengah yang terletak di bagian selatan Pulau Jawa. Sesar normal ini merupakan bagian dari rangkaian Pegunungan Serayu Selatan di bagian ujung timur (Van Bemmelen 1970). Diantara Pegunungan Lipatan Serayu bagian selatan dan Tinggian Vulkanik Purba Kulon Progo dibatasi oleh Sungai Bogowonto. Pada jalur inilah sesar normal Bogowonto berada (Gambar 2).

Sesar Bogowonto dipengaruhi oleh gaya stress atau arah tegasan yang berhubungan dengan interaksi tektonik di selatan Jawa. Di selatan Pulau Jawa terdapat zona penunjaman Lempeng Samudera Hindia-Australia di bawah Lempeng Benua Eurasia, yang memberikan efek kompresif terhadap bagian selatan Jawa. Dibagian barat Sesar Bogowonto berkembang deformasi ductile yang membentuk 


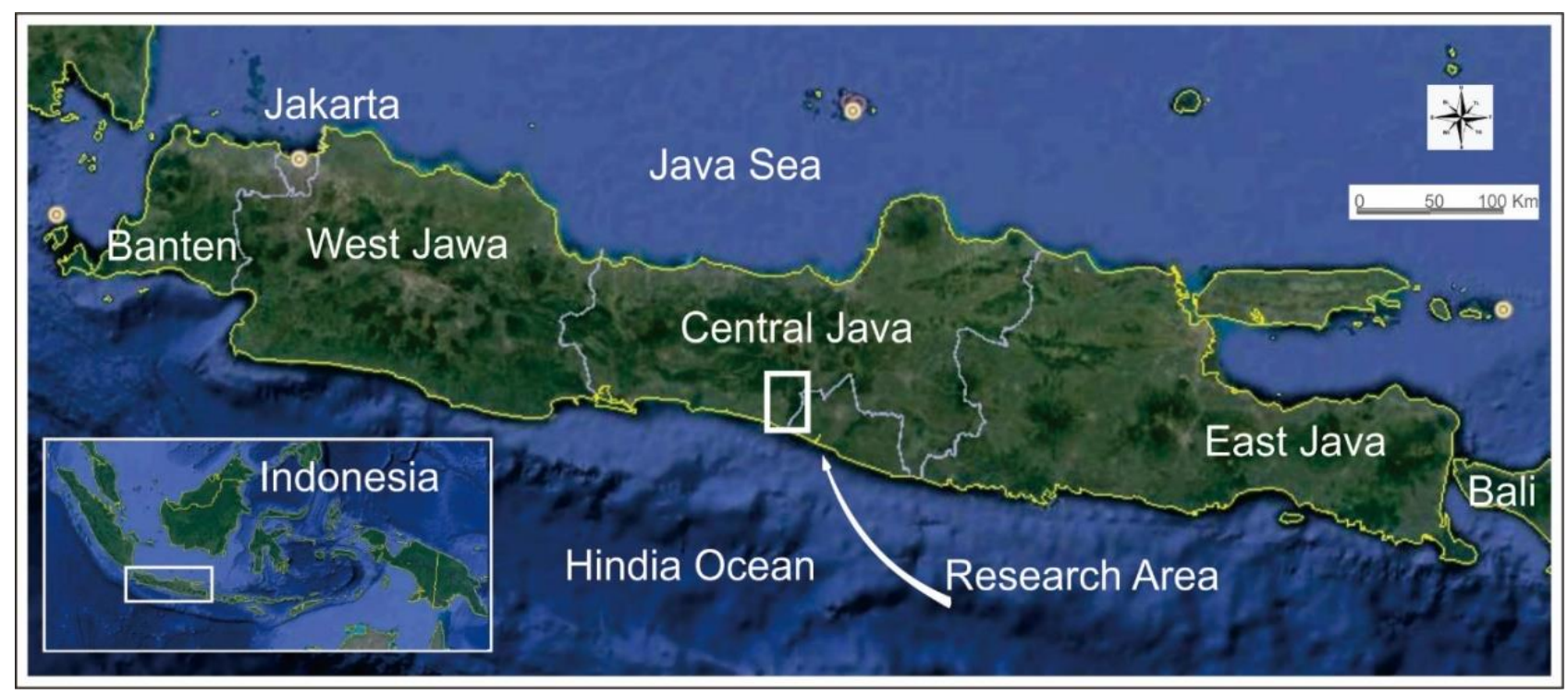

Gambar 1. Peta lokasi penelitian

pegunungan antiklin dan sinklin Serayu Selatan, sedangkan disebelah timurnya terdapat deformasi brittle yang membentuk pegunungan vulkanik Kulon Progo (Asikin et al., 1992). Sesar kompresif Kulon Progo dengan pergerakan mendatar mengiri hadir di pegunungan vulkanik Kulon Progo (Widagdo et al., 2016, 2017, 2018, 2019).

Sesar normal Bogowonto menjadi penting sebagai batas deformasi ductile/plastis yang membentuk lipatan sinklin-antiklin (Sujanto \& Sumantri, 1977; Van Bemmelen, 1970) di sebelah barat dan deformasi britle/rapuh membentuk patahan mendatar di sebelah timur (Widagdo et al., 2017, 2018, 2019). Semua penelitian di atas belum membahas secara mendalam mengenai jenis dan karakter Sesar Normal Bogowonto. Penelitian ini memberikan penjelasan mengenai jenis dan karakter Sesar normal Bogowonto.

\section{Tinjauan Geologi Regional}

Stratigrafi sebelah timur daerah kajian termasuk dalam Mandala Gunung Api Purba yang disusun terutama oleh batuan vulkanik Formasi Andesit Tua serta Formasi Sentolo/Jonggrangan (Van Bemmelen, 1970). Batuan Formasi Nanggulan dan Formasi Andesit Tua tersebut diintrusi oleh batuan intrusi dangkal berupa mikrodiorit, andesit dan dasit (Rahardjo et al., 2012). Batuan intrusi di daerah Kulon Progo terjadi dalam dua periode, yaitu intrusi yang terjadi pada Kala Oligosen Akhir-Miosen Awal dan Miosen Akhir. Kelompok gunungapi ini ditutupi secara tidak selaras oleh endapan karbonat laut dangkal Formasi Jonggrangan dan Formasi Sentolo (Harjanto, 2011).

Sebelah barat daerah kajian, berkembang tatanan stratigrafi yang masuk dalam tatanan stratigrafi Pegunungan Serayu Selatan (Asikin et al., 1992). Litologi yang dijumpai merupakan bagian dari Formasi Halang dan Formasi Peniron. Batuan Formasi Halang merupakan batuan vulkaniklastik berlapis baik yang berumur Miosen Akhir-Pliosen. Formasi Peniron merupakan batuan terutama tersusun atas breksi gunung api yang berumur Pliosen.

Dalam peta goelogi regional, di sebelah barat daerah kajian terdapat sesar N-S dengan pergerakan mendatar mengiri di utara daerah Kutoarjo (Asikin, 1992). Sesar mendatar ini memotong sesar naik berarah E-W pada Formasi Halang dan Formasi Peniron (Gambar 2). Formasi Peniron merupakan kelompok formasi batuan yang berumur Pliosen. Berdasarkan umur batuan termuda yang dipotongnya, gaya pembentuk sesar ini aktif pada pasca Pliosen. Off-set gerak mengiri pada sesar ini di mungkinkan terjadi oleh intervensi gaya dari sesar sinistal Kulon Progo yang mengalami reorientasi ke arah NW.

Lipatan antiklin dan sinklin terpotong oleh patahan N-S dengan off-set mengiri diantara daerah Kutoarjo (Purworejo) dan daeran Karangsambung (Asikin et al., 1992). Terdapat kelurusan jalur vulkanik berumur Miosen dengan arah E-W di selatan Jawa Tengah (Purwasatriya et al., 2019a). Terdapat sesar naik yang diinterpretasikan sebagai bagian kehadiran positive flower structure yang menyingkap batuan pra-Tersier di Karangsambung, sebelah barat daerah kajian (Purwasatriya et al., 2019b). 


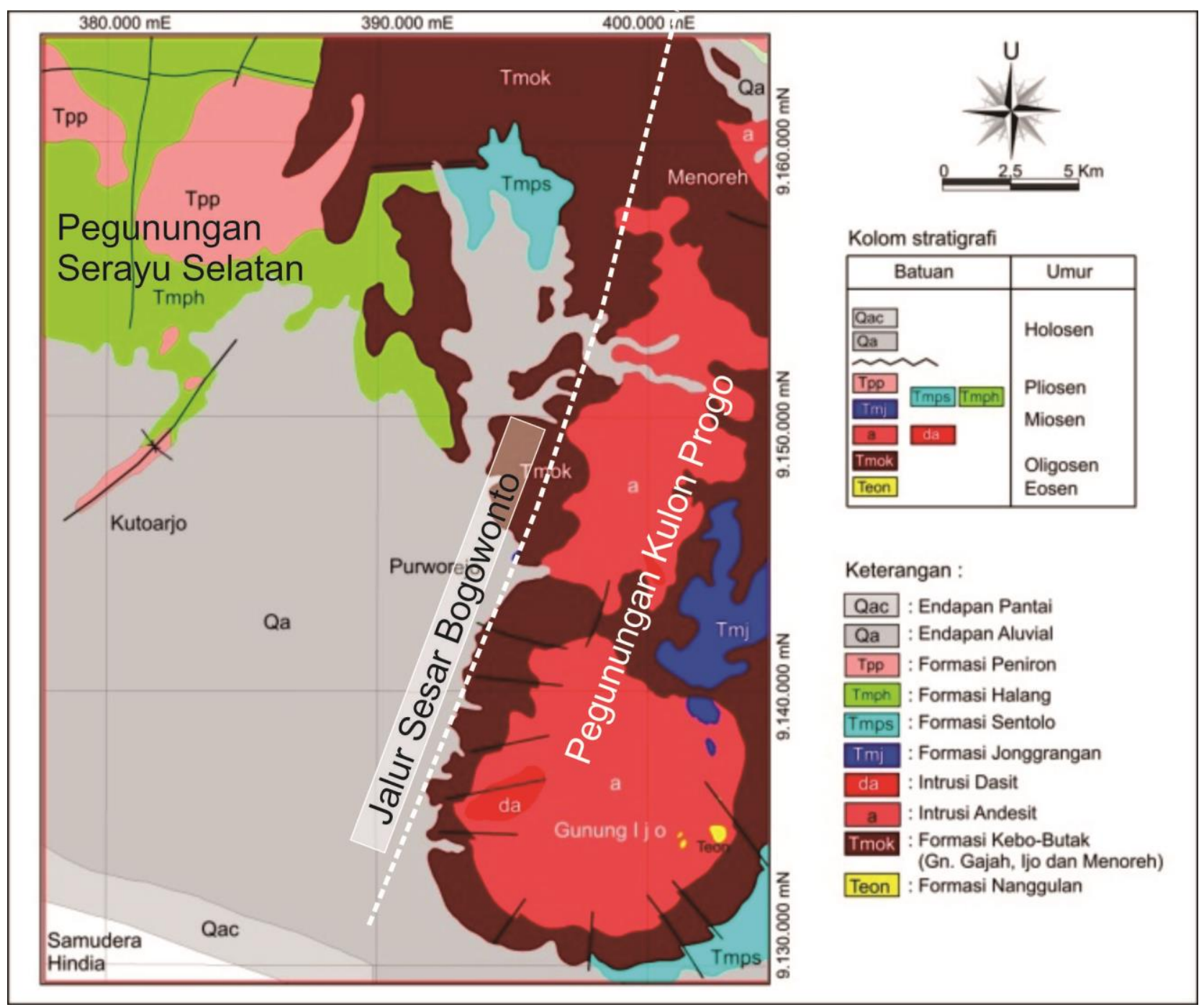

Gambar 2. Stratigrafi regional daerah penelitian menurut peta geologi regional lembar Yogyakarta menurut Rahardjo et al., (2012) dan peta geologi lembar Kebumen (Asikin et al.,1992)

Rekonstruksi jalur subduksi di Jawa pada umur Kapur Awal, dimana di sebelah barat daerah kajian yakni di Karangsambung dijumpai zona tumbukan antara mikro-kontinen Jawa Timur dengan Pulau Jawa (Satyana, 2014). Sesar Normal Bogowonto termasuk sesar bawah permukaan yang tidak dapat diidentifikasi dari peta geologi karena adanya penutup berupa batuan sedimen berupa endapan alluvial dan endapan pantai (Subagio, 2008).

\section{Metode}

Metode penelitian melalui pengamatan citra/peta geologi regional, pengamatan lapangan terhadap batuan, pengukuran unsur-unsur struktur sesar, analisis data struktur dan pembuatan penampang geologi. Dari pengamatan dan analisis citra, digambarkan jalur kelurusan yang mempermudah pekerjaan pengambilan data sesar di lapangan dan penggambaran kemenerusan sesar. Pengukuran data lapangan yang digunakan dalam penelitian ini berupa striasi pada bidang sesar yang dijumpai dalam singkapan-singkapan batuan pada jalur sesar dan data kekar gerus serta breksi-sesar.

Data sesar dilakukan pengukuran dan perekaman data langsung di lapangan dengan pengukuran gores-garis meliputi strike, dip, sudut pitch dan arah pergerakan sesar. Pengukuran kemudian digambarkan pada stereonet lower hemisphere yang meliputi strike dan dip bidang sesar. Kemudian dibuat bidang bantu dengan terlebih dahulu membuat titik 90 derajat dari bidang sesar melewati pusat lingkaran dan titik 90 derajat dari titik pitch sepanjang gambar lengkungan bidang sesar (great circle). Dua titik ini kemudian dihubungkan dengan bantuan Schmidt net. Area kompresional merupakan area arah panah pitch atau pergerakan blok batuan (warna hijau) sementara daerah kompresional merupakan area belakang gambar pitch. Terdapat 4 buah lokasi pengukuran bidang sesar dengan goresgaris. 


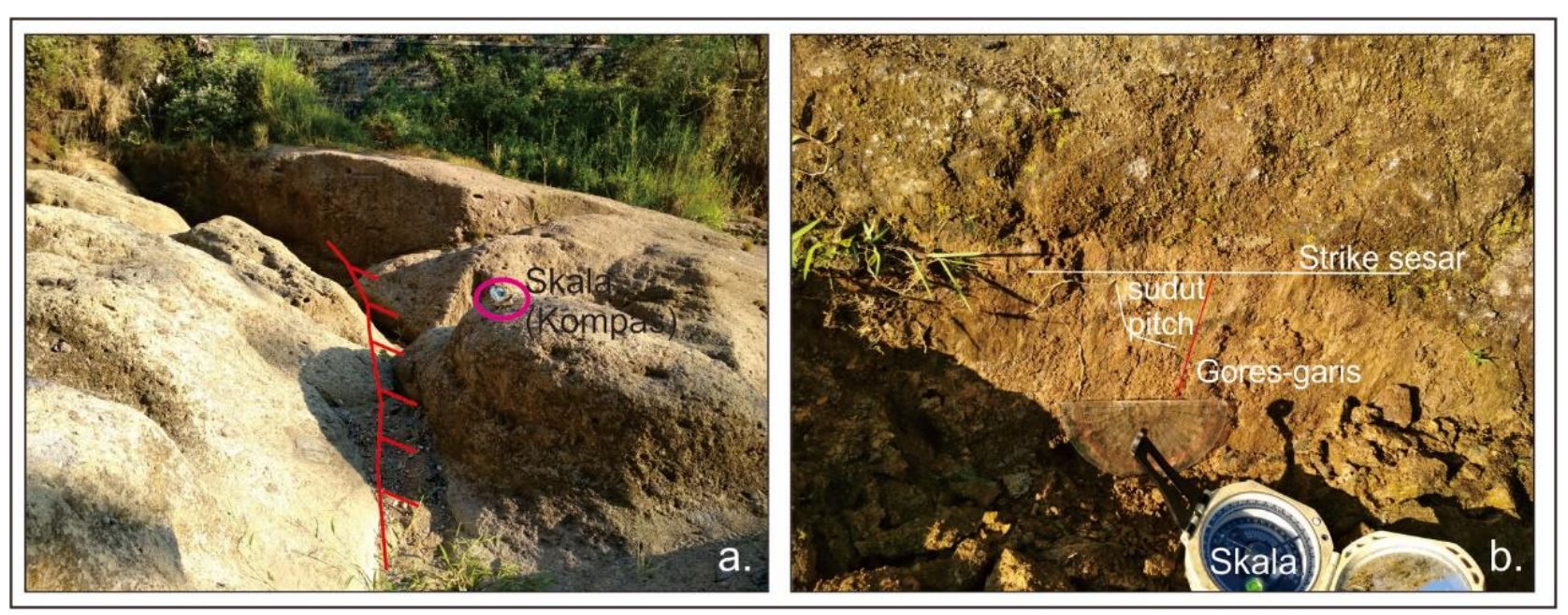

Gambar 3. Foto lapangan sesar normal Bogowonto di Desa Plipir Kecamatan Purworejo. a) Jalur Sesar Purworejo, b) gores-garis sesar normal dengan sudut pich menghadap ke baratlaut.

\section{Hasil dan Pembahasan}

Kehadiran sesar normal dijumpai di lapangan berupa bidang sesar dengan gores-garis dan kekar gerus di Kecamatan Purworejo, Kabupaten Purworejo. Sebuah bidang sesar dengan kedudukan strike/dip : N190\%/78 dijumpai dengan sudut pitch $86^{\circ}$ membuka ke arah barat laut (NW) (Gambar 3.b). Data sesar ini dijumpai pada batugamping di daerah Desa Brenggong. Sesar dengan kedudukan strike/dip : N193\% $/ 64^{\circ}$ dengan sudut pitch $82^{\circ}$ membuka ke arah selatan dijumpai di Desa Sidomulyo. Gores garis Sesar ini terbentuk pada batuan lava andesit sisi barat Gunung Gajah Barat. Di daerah Plipir dijumpai bidang sesar dengan kedudukan strike/dip : N190 $/ 62^{\circ}$ dan $\mathrm{N} 200^{\circ} / 77^{\circ}$. Sudut pitch yang dijumpai membentuk sudut masing-masing $75^{\circ}$ dan $60^{\circ}$ keduanya membuka ke arah utara.

Analisis terhadap data gores garis pada bidang sesar yang berkaitan dengan kehadiran sesar berarah relatif Utara Timurlaut-Selatan Baratdaya (NNE-SSW) digambarkan pada Gambar 4. Analisis data sesar ini menunjukkan adanya minimum horisontal stress direction berarah barat hingga baratlaut yang telah bekerja membentuk sesar-sesar normal berarah utara timurlaut-selatan baratdaya (NNE-SSW). Stress kompresi utama (T1) vertikal dengan gaya utama terlemah (T3) horisontal ke arah barat hingga baratlaut yang telah bekerja membentuk sesar-sesar normal dengan kemiringan (dipping) ke arah barat.

Analisis kekar gerus menunjukkan gaya terkuat (T1) relatif vertikal dan gaya utama terlemah (T3) berarah horisontal, menunjukkan tektonik bersifat regangan. Dengan demikian Sesar Bogowonto disimpulkan sebagai sesar normal (Gambar 5). Gambar ini memperlihatkan Formasi Jonggrangan terpotong sehingga di bagian timur ia berada pada daerah tinggian dan di sebelah barat ia berada pada daerah rendahan secara geomorfologi.

Sesar Bogowonto berada di sebelah barat Gunung Gajah dan Gunung Ijo. Kedua tubuh volkanik Tersier ini merupakan bagian dari Formasi Kebo-Butak dalam tatanan stratigrafi regional. Patahan Bogowonto memiliki arah relatif Utara Timurlaut-Selatan Baratdaya dan menjadi pembatas antara Pegunugan Serayu Selatan di sebelah barat dan Pegunungan Kulon Progo di sebelah timurnya. Jalur sesar Bogowonto ini tertutup oleh endapan aluvial di sebelah selatan dan endapan gunung api Sumbing Tua di sebelah utara (Gambar 2), sedang di bagian tengah memotong batuan Formasi Kebo-Butak dan formasi Jonggrangan (Gambar 4 dan 5).

Kajian sistem sesar dan lipatan di Jawa Barat, dengan mengacu kepada sistem tegasan di Pulau Jawa, maka struktur lipatan Serayu Selatan di sebelah barat daerah penelitian terbentuk oleh sistem tegasan kompresi dengan arah tegasan utamanya utara-selatan (Haryanto, 2015). Terkait dengan aspek stratigrafinya, seluruh struktur geologi tersebut terbentuk pada periode tektonik Akhir Tersier. Kajian lainnya juga melaporkan struktur berarah utara-selatan yang memotong batuan-batuan gunung api di Jawa Barat yang berumur Tersier Akhir (Sunardi, 2014).

Struktur geologi pada batuan Paleogen hingga Neogen di Pulau Jawa dihasilkan oleh arah jalur subduksi yang relatif sama, yaitu relatif berarah barat-timur (Haryanto, 2006). Posisi tumbukan ini menghasilkan sistem tegasan (gaya) berarah N-S (utara-selatan). Akibat dari sistem stress ini, batuan sedimen Tersier di Jawa mengalami proses perlipatan dengan sumbu lipatannya berarah E-W (barattimur/arah lipatan Serayu Selatan) atau dikelompokkan sebagai Pola Struktus Jawa. 


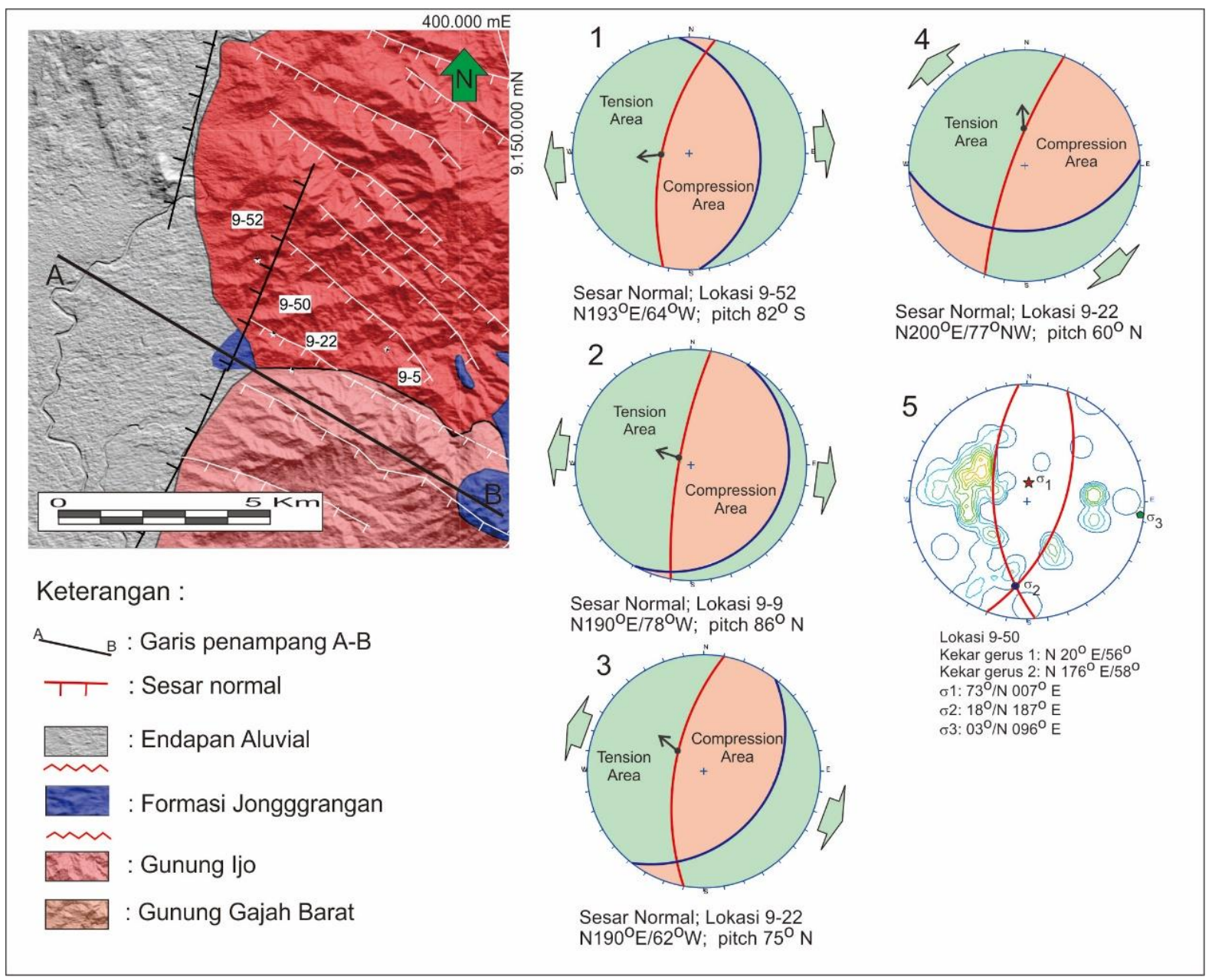

Gambar 4. Analisis sesar dan kekar pada jalur sesar normal ekstensional Bogowonto

Berdasarkan data seismotektonik dan kegempaan, disimpulkan Sesar Bogowonto sebagai sesar normal (Soehaimi, 2008). Penulis ini menjelaskan keberadaan sesar-sesar normal berhubungan dengan aktivitas tektonik tunjaman Jawa yang merupakan bagian dari satuan seismotektonik busur tektonik sangat aktif.

\section{Kesimpulan}

Patahan Normal Bogowonto dihasilkan oleh stress tarikan (least stress/T3) berarah barat-timur hingga baratlaut-tenggara yang telah bekerja menciptakan sesar normal utara-selatan $(N-S)$ dengan kemiringan (dipping) ke arah barat. Sesar ini menjadi batas cekungan sedimentasi dominan klastik di sebelah barat dan dominan vulkanik di sebelah timur dan batas deformasi ductile di sebelah barat dan deformasi britle di sebelah timur.

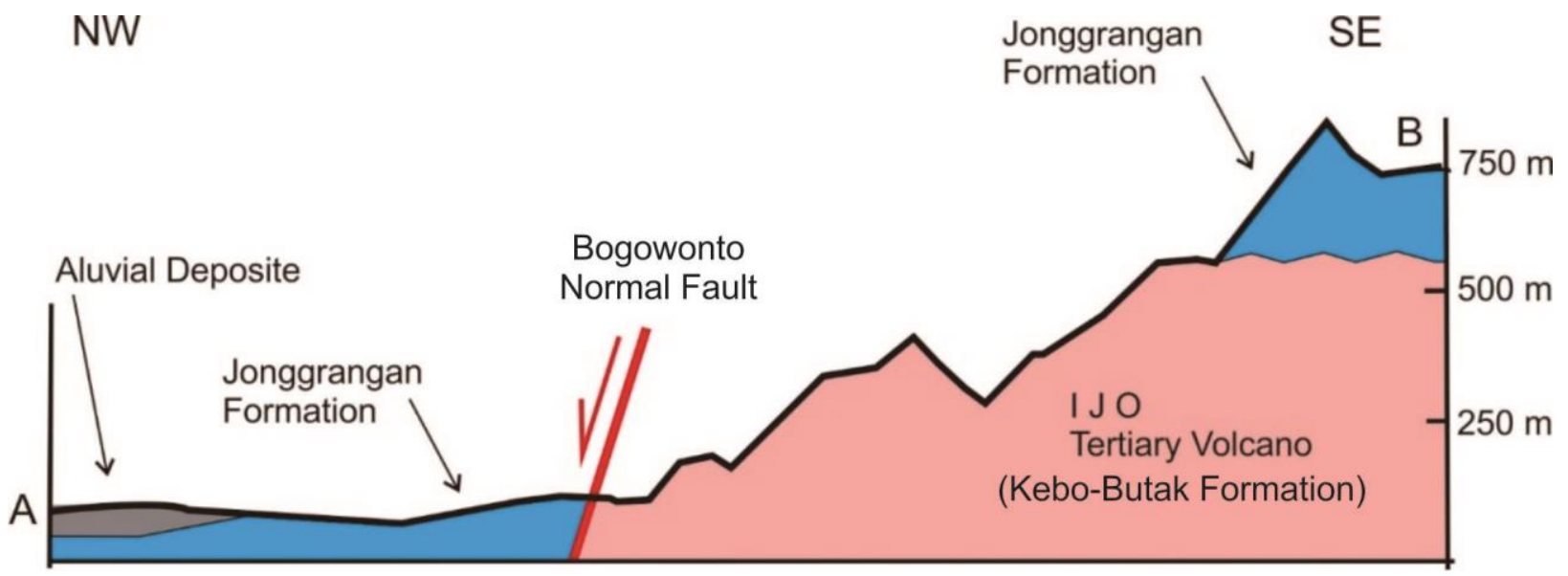

Gambar 5. Penampang geologi dari garis penampang A-B pada Gambar 4 


\section{Ucapan Terima Kasih}

Terimakasih kami sampaikan kepada rekan-rekan di Jurusan Teknik Geologi Universitas Jenderal Soedirman yang telah banyak membantu dalam penelitian dan penulisan publikasi ini.

\section{Referensi}

Asikin, S., Handoyo, A., Busono, H. dan Gafoer, S., (1992). Peta Geologi Lembar Kebumen, Jawa. Pusat Penelitian dan Pengembangan Geologi, Bandung, Skala 1:100.000.

Bachri, S., (2014). Pengaruh Tektonik Regional Terhadap Pola Struktur dan Tektonik Pulau Jawa. JGSM Vol. 15 No. 4, hal 215-221.

Harjanto, A., (2011). Vulkanostratigrafi di Daerah Kulon Progo dan Sekitarnya, Daerah Istimewa Yogyakarta. Jurnal Ilmiah MTG, Vol. 4 No. 2, Yogyakarta.

Haryanto, I., (2006). Struktur Geologi Paleogen dan Neogen di Jawa Barat. Bulletin of Scientific Contribution. Vol. 4, No., 1, 88-95

Haryanto, I., (2015). Struktur Sesar di Pulau Jawa Bagian Barat Berdasarkan Hasil Interpretasi Geologi. Bulletin of Scientific Contribution, Volume 11, Nomor 1, 1-10.

Purwasatriya, E. B., Surjono, S.S. dan Amijaya, D. H. (2019a). Sejarah Geologi Pembentukan Cekungan Banyumas Serta Implikasinya Terhadap Sistem Minyak dan Gas Bumi. Jurnal Dinamika Rekayasa, Vol. 15 No. 1 Hal. 25-34.

Purwasatriya, E.B., Amijaya, H. and Widagdo, A., (2019b). Karangsambung : Sebuah Positive Flower Structure? Studi Pendahuluan Tersingkapnya Batuan Tertua di Jawa. Seminar LIPI-Kebumen.

Rahardjo, W., Sukandarrumidi, Rosidi, HMD., (2012). Peta Geologi Lembar Yogyakarta. Pusat Penelitian dan Pengembangan Geologi, Bandung.

Satyana, A.H., (2014). New Consideration on The Cretaceous Subduction Zone of Ciletuh-Luk UloBayat-Meratus : Implications for Southeast Sundaland Petroleum Geology. Proceeding IPA, 38th annual convention and exhibition, Jakarta.

Soehaimi, A., (2008). Seismotektonik dan Potensi Kegempaan Wilayah Jawa. Jurnal Geologi Indonesia, Vol. 3 No. 4, 227-240.

Subagio, (2008). Struktur Geologi Bawah Permukaan Daerah Kebumen Berdasarkan Analisa Pola Anomali Gaya Berat dan Geomagnet. Jurnal Geo-Sciences JSDG, Vol 18. No. 6.

Sujanto, F.X. and Sumantri, Y.R., (1977). Preliminary Study On The Tertiary Depositional Pattern Of Java, Proceedings Indonesian Petroleum Association, $6^{\text {th }}$ Annual Convention.

Sunardi, E., (2014). Kontrol Struktur Terhadap Penyebaran Batuan Volkanik Kuarter dan Gunungapi Aktif di Jawa Barat. Bulletin of Scientific Contribution, Volume 12, Nomor 3, 119-123.

Van Bemmelen, R.W., (1970). The Geology of Indonesia. Vol. IA, General Geology of Indonesia and Adjacent Archipelago, Government Printing Office, The Hague.

Widagdo, A., Pramumijoyo, S.P., Harijoko, A., Setiawan, A., (2016). Kajian Pendahuluan Kontrol Struktur Geologi Terhadap Sebaran Batuan-Batuan Di Daerah Pegunungan KulonprogoYogyakarta, Proceeding Seminar Nasional Kebumian ke-9, TG FT-UGM, Yogyakarta.

Widagdo, A., Pramumijoyo, S.P., Harijoko, A., (2017). Rekontruksi Struktur Geologi Daerah Gunung Ijo Di Pegunungan Kulon Progo-Yogyakarta Berdasarkan Sebaran Kekar, Sesar dan Urat Kuarsa, Proceeding, Seminar Nasional Kebumian Ke-10, TG FT-UGM, Yogyakarta.

Widagdo, A., Pramumijoyo, S.P. and Harijoko, A., (2018). Morphotectono-Volcanic of Tertiary Volcanic Rock In Kulon Progo Mountains Area, Yogyakarta-Indonesia, International Conference On Earth Science, Mineral and Energy (ICEMINE), UPNV Yogyakarta.

Widagdo, A., Pramumijoyo, S.P. and Harijoko, A., (2019). Pengaruh Tektonik Kompresional Baratlaut-Tenggara Terhadap Struktur Bidang Perlapisan, Kekar, Sesar dan Lipatan di Pegunungan Kulon Progo-Yogyakarta. Jurnal GEOSAPTA Vol. 5 No.2 DOI: 10.20527/jg.v5i2.6211 